Journal

of Geography,

Politics and Society

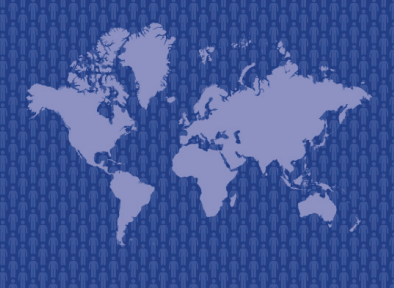

$10(1) / 2020$

\section{Journal of Geography, Politics and Society}

2020, 10(1), 1-8

https://doi.org/10.26881/jpgs.2020.1.01

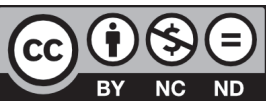

\title{
ONE SMALL STEP FOR E-VOTING, ONE GIANT LEAP FOR DEMOCRACY
}

\author{
Marina Gorbatiuc \\ Institute of Legal, Political and Sociological Research, Stefan cel Mare 1, MD 2001 Chisinau, Moldova, \\ e-mail: marina.gorbatiuc@mail.ru
}

\section{Citation}

Gorbatiuc M., 2020, One small step for e-voting, one giant leap for democracy, Journal of Geography, Politics and Society, $10(1), 1-8$.

\begin{abstract}
E-voting is the next step of the Republic of Moldova evolution. The article presents advantages of e-voting, all steps of using it, and its many types. Electronic voting refers to elections using electronic means. E-voting can be managed by phones, the Internet, private computer networks or special kiosks. Reasons for accepting this kind of voting are provided.

The analyzed in the article OSCE/ODIHR's (Office for Democratic Institutions and Human Rights) activities which are related to tolerance and non-discrimination are focus on the following areas: legislation; law enforcement training; monitoring, reporting on, and following up on responses to hate-motivated crimes and incidents; as well as educational activities to promote tolerance, respect, and mutual understanding.

Conclusions from all ODIHR activities which are carried out in close co-ordination and co-operation with OSCE participating States, OSCE institutions and field operations, as well as with other international organizations are given.
\end{abstract}

\section{Key words}

electronic voting, tolerance and non-discrimination, ODIHR's (Office for Democratic Institutions and Human Rights), international organizations, the Republic of Moldova.

Received: 23 September 2019

Accepted: 15 January 2020

Published: 31 March 2020

\section{Introduction}

Electronic voting (also known as e-voting or EVM) refers to voting using electronic means either to aid or take care of the chores of casting and counting votes.

Electronic voting is often seen as a tool for making the electoral process more efficient and for increasing trust in its management. Properly implemented, e-voting solutions can increase the security of the ballot, speed up the processing of results and make voting easier. However, the challenges are considerable. If not carefully planned and designed, e-voting can undermine the confidence in the whole electoral process (Wolf et al., 2011).

According to the opinions of theorists and experts, contemporary civilization faces the electronic democracy era, based on employing information and communication tools into various fields of human life. One may thus state that democracy "supported" by modern technologies evolves and begins to function in a new reality, acquiring new dimensions (Musiał-Karg, 2014). Some theoreticians of democracy, e.g. B.N. Hague or B. Loader, - even speak 
of the change in the way of understanding a democratic system (Hague, Loader (eds.), 1999). Referring to such an attitude, B.R. Barber (2003) - introduces the notion of strong (powerful) democracy, and attributes to it a series of virtues - e.g. activeness, engagement, duty. Democracy enriched with electronic tools (electronic democracy, e-democracy) - e.g. electronic voting, may reinforce democracy, increase the level of participation among eligible voters, and thus legitimize decisions taken.

The world is in the era of globalization. Information technology has greatly affected all aspects of life, and to a large extent, this includes politics. The idea behind developing an online voting system was to improve and speed up the process of the traditional way of voting. The concept of e-voting should be embraced by the developing countries because of its advantages over the traditional manual voting system.

Voting is a method by which groups of people make decisions. These decisions could be political, social or public. Voting can also be used to choose between difficult plans of actions or to decide who is best eligible to be awarded a prize. Voting can thus be defined as a process that allows a group of individuals to choose between a numbers of options. Most voting systems are based on the concept of the majority rule or plurality. For example, in an election, a candidate with a plurality receives more votes than any other candidate, but does not necessarily receive the majority of the total votes cast. Elections allow the people to choose their representatives and express their preferences for how they will be governed. Naturally, the integrity of the election process is fundamental to the integrity of democracy itself. The election system must be sufficiently robust to withstand a variety of fraudulent behaviors and must be sufficiently transparent and comprehensible so that voters and candidates can accept the results of an election. A voting system must be comprehensible to and usable by the entire voting population, regardless of age, infirmity, or disability. Providing accessibility to such a diverse population is an important engineering problem and one where, if other security is done well, electronic voting could be a great improvement over the current paper systems.

\section{Results and Discussion}

We would like to emphasize that the Ministers' Deputies adopted at their 1289th meeting. The new recommendation was developed to ensure that electronic voting complies with principles of democratic elections and is the only existing international standard on e-voting so far. The new recommendation deals with the most critical part of election technology, namely e-voting, which means the use of electronic means to cast and count the vote. This category includes systems such as Direct Recording Electronic (DRE) voting machines, ballot scanners, digital pens and internet voting systems. It aims to harmonize the implementation of the principles of democratic elections and referendums when using e-voting, thus building the trust and confidence of voters in their respective voting process and e-voting schemes (Council of Europe..., 2017).

The public thirst for rapid and objective results has led developing countries to adopt new technology in the electoral process. Automation is often a complicated process, especially in countries with limited infrastructure. Technology, impacts all aspects of elections, including those that seem immune, but eventually may lead to unintended con-sequences. It is obvious that a manual way of conducting election could be difficult to determine transparency in an election process. We carefully identified the following problem associated with the election processes as: the absence of an online registration system where people of voting age can simply logon and register at any time and place convenient to them. There is also a problem of conveying the election result from a pooling unit to the collation center, where the election officials maybe attacked. Paper balloting may be damaged as a result of rain-fall or other external interference.

People sometimes are unwilling to participate in elections because of the system of election. The traditional system requires people to stand in line for hours to get the chance to vote, while they also have a lot of routine activities to do (Bonetti et al., 2000). Online voting, on the other hand, gives a large opportunity to vote from any point where Internet access is available, such as home, school, office or even a shopping mall. Using online voting can reduce the time people need to vote. This means that citizens can vote without waste of time and to avoid long queue of voters which were identified as the biggest problem of every election. Citizens can vote without going to the polls, and this may be an efficient way to encourage people's participation on the Election Day. In other countries where democracy is celebrated, like the United States and the United Kingdom, election time is a period of looking forward to change, a new hope for better leadership.

The introduction of the electronic voting has eased the way voting is conducted. The term evoting is used for the variety of different ways of voting where the voter's intention is expressed and 
collected using the electronic methods. These technologies have reduced a significant amount of time in conducting the elections and announcing the results. These technologies have also reduced the manpower that used to be spent on the traditional voting system. Electronic voting, also known as evoting, is simply voting electronically by deploying biometrics to achieve accuracy.

Electronic voting technology can speed the counting of ballots, reduce the cost of paying staff to count votes manually and can provide improved accessibility for disabled voters. However, there has been contention, especially in the United States, that electronic voting, especially DRE voting, could facilitate electoral fraud and may not be fully auditable. In addition, electronic voting has been criticized as unnecessary and expensive to introduce. While countries like India continue to use electronic voting, several countries have cancelled e-voting systems or decided against a large-scale rollout, notably the Netherlands, Germany and the United Kingdom due to issues in reliability of e-voting.

Electronic voting systems for electorates have existed in the USA since the 1960s when punched card systems debuted. Their first widespread use was in the USA where 7 counties switched to this method for the 1964 presidential election. The newer optical scan voting systems allow a computer to count a voter's mark on a ballot. DRE (a direct-recording electronic voting machines), which collect and tabulate votes in a single machine, are used by all voters in all elections in Brazil and India, and also on a large scale in Venezuela and the United States. They were also used on a large scale in the Netherlands but have been decommissioned after public concerns.

Voting systems have been around for hundreds of years and, despite different views on their integrity, have always been deemed secure with some fundamental security and anonymity principles. Numerous electronic systems have been proposed and implemented, but some suspicion has been raised regarding the integrity of elections due to detected security vulnerabilities within these systems.

Internet voting systems have gained popularity and have been used for government elections and referendums in Estonia and Switzerland as well as municipal elections in Canada and party primary elections in the United States and France.

There are also hybrid systems that include an electronic ballot marking device (usually a touch screen system similar to a DRE) or other assistive technology to print a voter verified paper audit trail, then a separate machine for electronic tabulation was used.
As a matter of fact there will always be people who will try to stop any beginnings and those who will remain in history, because they helped our civilization to develop. But the places where we have lived have changed, rulers have changed and ways of leading have changed during history. The leading system in most developed countries is democracy. Although the most aspects in democracy have changed, some remain the same as many years ago. Voting is such a thing. During many years people used to lose a lot of time to vote, thronging for many hours to throw a piece of paper in a basket. History is repeating itself: there are two kinds of people nowadays. People who say that everything is perfect and we should remain at the same level, because that is what they are used to, and there are those who want to make our life easier by triggering progress. We believe that e-voting is the next step in developing democracy. E-voting is voting using electronic means either to aid or take care of the chores of casting and counting votes.

In 1856, The Australian state of Victoria became the first place to use uniform official ballots. This style of paper ballot listed the names of all candidates and issues in a fixed order, was counted by hand (Bellis, 2000). Concern about vote fraud and voter privacy was not restricted to England and the United States. One of the most important innovations in voting technology came about in Australia. In 1858, an election was held in the state of Victoria using standardized paper ballots that listed all candidates for office. These ballots were printed at government expense and distributed to the voters at the polling place, one per voter. This system, while obvious in retrospect, was sufficiently innovative to be known as the Australian secret ballot.

From today's viewpoint, the Australian ballot seems so natural that we take it for granted as ancient technology, and in much of the world, it is so firmly entrenched that replacing it with mechanical or electronic voting machines is unthinkable. Nonetheless, the benefits of the Australian ballot were not obvious at the time it was introduced. Use of this technology requires, after all, a special print run at government expense, plus the cost of secure ballot storage and transport.

Faculty from the California Institute of Technology and the Massachusetts Institute of Technology created the Voting Technology Project in the wake of the 2000 election to provide "strong academic guidance in this intersection of technology with democracy." They offered several recommendations to improve election administration for the future in their July 2001 report (What Is and What Could Be) (Caltech/MIT, 2001). In May 2002, the FEC released 
an updated version of the standards for electronic voting systems. In July 2004, Nevada became the first state to mandate that all electronic voting machines used for federal elections be equipped with printers that produce a voter-verified paper audit trail (Heller, 2004).

The general online voting system has been divided into six phases. These are:

- registration;

- authentication;

- voting and saving the votes;

- managing the votes;

- counting the votes;

- auditing.

We are agree that e - voting systems have many advantages and disadvantages:

Increased turnout: One of the biggest advantages of using online voting system is that it could increase the voter turnout. The implementation of e-voting in Estonia saw an increase in voter turnout. They increased from $47.4 \%$ in the 2005 local elections to $63.5 \%$ in the 2011 parliamentary elections, a $16.1 \%$ jump. This is not surprising given that evoting makes it more accessible and convenient for citizens to vote (Khairul Anwar, 2009).

Convenience: An online voting system will provide citizens the comfort of voting from their own place at their own time. This will also help citizens who are abroad and using special mail ballot to send their vote. Also the people who are out of the country for the military service can take advantage of this project.

Appeal to young voters: Online voting would attract young voters to vote. The voter turnout among young people is particularly low. The Canadian survey shows that $64 \%$ of the young voters who did not vote would prefer to vote online.

Reduce the expenses: An online voting system will help reduce the expenses involved in the setting up the polling sites and save money in printing and mailing the paper ballot. It will also reduce the expenses on the manpower.

More information on the candidates: An online voting system will allow more information to be displayed about the candidates and their policies.

Comprehensive reporting: An online voting system will instantly provide the informative day-byday statistics about the elections beyond just who has won.

Save paper: Online voting will also help save tons of paper. Thus it will contribute to protecting the environment.

Issues with online voting: There are different issues that need to be considered before developing an online e-voting system. The main issue is security.
There are other aspects beside security. Some of them are forcibility, vote selling, vote solicitation, registration, etc.

Malicious payload: There are so many programs available that they can threaten the concept of online voting. The hacker only needs to visits the website of any number of security vendors. Once the malicious payload reaches the host or voting platform, it can cause lot of harm that no one can imagine. This program can change the voter's vote without anyone knowing it regardless of any kind of encryption or voter authentication in place. The main threat with this program is that it can manipulate the votes before the authentication is applied and it erases itself after causing the damage so that there is no evidence of the voting manipulation and fraud.

Selling of the votes: This issue is a matter of concern, and it is nearly impossible to stop until people realize what difference a single vote can make. It happened in the past that people sold their votes for money. No matter how secure the system, it cannot do anything if the person sells his online voting details to someone else.

Fraud: This issue comprises the registration part and the voting part. The voter can register more than once online as there is none to see and can vote more than once. There is no point of having election if the voter votes more than once using false identity.

Further work needs to be done in designing and incorporating extra protocols into the existing one for elections where voters need to vote for multiple candidates at various levels of the government (for example a voter needs to vote for candidate $X$ for presidency, $Y$ for senate and $Z$ for governor of a state, etc.) at a go without having to vote individually for every candidate at separate times. The day is not far when e-voting will be the norm, and people can exercise their franchise via the internet from their own house rather than go to the voting zone without any corruption. But voters must have a substantive reason for trusting that their intentions have been correctly interpreted and recorded, and that their votes have been counted correctly. Future intention regarding electronic voting should improve our capability and increase our knowledge in all the areas of cyber security (Statistics...). The new technology should be improved in such way - that anyone can ensure that the intent of the voters is reflected in the official tally of the vote, that they are credible when margins of victory may be as small as a fraction of a percent. Thus the future electronic voting environment would satisfy the needs of voters and election officials. Thus new rules and reliable, trustworthy voting systems would win over voters and would be known as the solution that overcomes the 
constraints and saves democracy (The Constitutionality..., 2009).

We want to present a comparison of e-voting between Estonia, Germany and the USA.

Electronic voting in Estonia began in October 2005 during local elections when this country became the first to have legally binding general elections using the Internet as a means of casting the vote and was declared a success by the Estonian election officials. From 2005 till 2009 we can see a progressive growth in the number of participants in elections. Voters who have participated in remote voting via the internet in Estonia have been on the steady increase over the years from $0.9 \%$ in 2005 , to $3.4 \%$ in 2007 and in 2009 it was $9 \%$ of all eligible voters. (Chowdhury, 2010).

It is not clear if e-voting could raise the level of voter turn-out. However, it is a measure, which may hinder the steady decrease of turn-out percentage. Remote e-voting is regarded as an added value to the voter and a measure of widening of the democracy. Growth of online interaction and presence can be witnessed by the exponential increase in the number of people with home computers and Internet access. Since the idea of e-voting became public in 2001, many people in Estonia expect that e-voting becomes an integral part of today's information society as soon as possible. There are strong views that rapid developments of information society should be taken into account in state's democratic practice (Maaten, 2004).

We can assume that e-voting in Estonia, when fully analyzed, does not produce the feared political effects that become apparent at first sight. This is rather good news to promoters of e-voting, as political biases introduced due to changes in voting procedures are rarely seen as being "innocent". We believe that in the Estonian case the introduction of e-voting was politically rather innocent, indeed (Breuer, Trechsel, 2006).

Germany piloted its first electronic voting machines, supplied by the Dutch company NEDAP, in Cologne in 1998. The attempt was seen as successful, and one year later Cologne used electronic voting machines for its entire European Parliament elections. Soon other cities followed suit, and by the 2005 general election nearly 2 million German voters used these NEDAP machines to cast votes. Reaction to the use of these electronic voting machines was generally very positive among voters, who found the machines easy to use, and among election administrators, who were able to reduce the number of polling stations and staff in each polling station (Branscomb, 2007).
Electronic voting also known as e-voting is the type of vote were the election data is stored, recorded and primarily processed as digital information. These electronic vote systems have been used since the 1960s. E-voting in the USA was first used in 1964, when 7 counties switched to this method for the presidential election. E-voting referred to computerized vote machines which used electronic ballots for voting instead of paper ballots (Electronic Voting in the USA).

In 2017, election systems received critical infrastructure designation under the Department of Homeland Security (DHS). The DHS is tasked with protecting the nation from attack. In addition to more obvious attacks against the United States, DHS is also charged with defending the nation against non-linear warfare tactics like propaganda and cyber campaigns. Soft power has gained popularity amongst US competitors because the US has dominated militarily for so long that hard power competition is not reasonable. Hybrid warfare strategies present a way to circumvent US counteraction, exploit the US binary notion of "war" and "peace", and undercut the US integrity. Competitors flex soft power through propagandistic campaigns that phenomenalize intentionally divisive issues that may not be grounded in truth: fake news tailored to sow chaos, confusion, and divisiveness.

Attacking election systems is just another way in which adversaries undermine US power. The 2016 US presidential election represents the first time in the modern world in which a country as powerful as the US had its election undermined by a global underdog. Russian propaganda successfully affected an American presidential election outcome. Attacks by foreign adversaries will not stop now. Cyber warfare campaigns are inexpensive and effective; attribution is hard, and attacks are scalable. Ahead of the 2020 presidential election, the US and other democratic states anticipate a rise in disruptive activities by bad actors; these attacks will persist as they intensify in the coming years.

The general rule of security is that systems are only as strong as its weakest link. Some states are not aligned with others in terms of what i's at risk. Of 350,000 electronic voting machines in use today, some machines are more vulnerable than others ("The Crisis of Election Security" 2018). No individual state is equipped to withstand an attack on their election infrastructure; it i's not in the job description. The confluence of the rise of competent, sophisticated, and motivated external threats; the failures of internal systemic governance and policies; and the inherent vulnerabilities in electronics bring 
to bear a new question: can we protect American democracy? (Cheng, 2019)

Nowadays electronic voting is also used in other countries like: Brazil, Norway, Germany, Venezuela, India, Canada, Belgium, Romania, Australia, the UK, Italy, Ireland, France.

As about the Republic of Moldova, we would like to give our point of view. The Republic of Moldova is a parliamentary republic. Executive powers are exercised by the government headed by a prime minister and legislative power is vested in the parliament. The president serves as the head of the state and holds certain limited authority, including on foreign policy and national defense.

As described, the right to vote is one of the fundamental human rights as provided by the Universal Declaration of Human Rights, relevant international and European human rights treaties, including the International Covenant on Civil and Political Rights, the International Covenant on Economic, Social and Cultural Rights, and the European Convention for Human Rights. The introduction of Internet voting will provide for additional opportunities for men and women, in particular for those with mobility disabilities; for citizens residing abroad who are willing to vote, but do not have the possibility because the overseas polling stations are far away from them; for internal migrants, including students; as well as for the Moldovan citizens who are residing in the Transnistria region.

Recently, the E-Governance Center of the Republic of Moldova, the national coordination authority of open data and online public services, have initiated the process of public consultations on a new Action Plan on Open Government for the years 2016-2018 (Vino cu propuneri..., 2016). Thus, as the implementation of open governance principles shall not be limited to the Governmental bodies, it is recommended that relevant actions for the preparation, piloting and introduction of Internet voting in Moldova should be introduced in the respective Action Plan. This will contribute to the synergy of actions of the Central Electoral Commission and Governmental authorities in the implementation of the piloting of Internet voting by the regular 2018 national parliamentary elections.

According to the official data presented by the report of Grammar Social Media in February 2018, $70 \%$ of the households in Moldova do have access to the Internet, $72 \%$ of users access the Internet at least once a day (Peste 900 de mii..., 2018). The penetration rate for the Internet service - (land ADSL, fiber) is $14.7 \%$ (over 525,000 households). At the same time, according to the report of the National Regulatory Agency for Electronic Communication and
Information Technology the mobile telephone penetration rate is $121.8 \%$ (over $4.3 \mathrm{mln}$. users), while mobile data penetration rate is over $8.5 \%$ (with over 298,400 users) (Market Evolution:..., 2016).

According to www.Internetlivestats.com, there are 1,946,111 Internet users in Moldova, which represent $47.9 \%$ of the population of the Republic of Moldova in 2016 (Internet live...).

According to the information provided by the EGovernment Center, during the inception mission interviews, there are currently over 90,000 users of electronic signatures per year in Moldova, including over 55,000 users of mobile signatures (SIM) (Moldcell..., 2012), over 35,000 users of E-key (in particular legal persons and civil servants), over 200 users of E-ID cards.

The Republic of Moldova has a high penetration rate of the Internet and very good mobile coverage. The Internet is accessible almost everywhere in the country. Mobile phones and computers can be found in the majority of households, being very popular among individuals.

Parliamentary political parties expressed a general support for the introduction of Internet voting in the Republic of Moldova. The main motivation mentioned in this regard was the creation of alternative voting solutions for Moldovans living abroad, the young electorate (the participation rate of the youth in the previous Parliamentary Elections was less than 5\%) and for those who usually do not vote in elections due to other agendas during the Sunday Election-Day. However, the majority of the political parties where rather reserved to predict the introduction of Internet voting in the Republic of Moldova in the next 2-4 years. At the same time, all representatives of the political parties have expressed support for the piloting of Internet voting during the next ordinary Parliamentary Elections. Some also indicated that a preliminary piloting phase could be considered as well for the Elections of the President scheduled for 30 October 2016. Special attention will be dedicated to the testing and piloting phases. Visibility and popularization of Internet voting was also mentioned as important.

The Republic of Moldova has all the basic preconditions for introducing Internet voting in the near future:

1. Well - developed Internet infrastructure.

2. High degree of mobile network coverage.

3. Good degree of public ICT literacy.

4. Reliable voters list (SRV).

5. All polling stations are equipped with Internet connected computers, and they are constantly online and communicating with SAISE. 
Despite the fact that the absolute number of bearers of digital certificates for personal identification are still low, popularity of Mobile-ID is rising rapidly, and it is expected to continue to grow as more e-services will be offered by the government.

Thus, the authors of this Study present two main propositions:

- to create an official Internet Voting Information System (IVIS);

- to implement the IVIS Pilot version before the general Parliamentary Elections in 2018.

The Electoral Code of the Republic of Moldova does not include specific provisions regulating Internet voting concepts, policies, rules, procedures, and relevant functioning and the management requirements for the Internet Voting Informational System. In order to create a proper legal framework for the implementation of Internet voting, the Electoral Code is to be modified by introducing Internet voting concepts, vote verification and cancellation rules, voting secrecy assurance principles, voter identification aspects, information systems establishing the framework for its functional, security and audit requirements and other elements common to the Internet voting. A new title on Internet voting shall be introduced in the Electoral Code. The Central Electoral Commission could also consider, if deemed necessary, to establish a separate Internet Voting Electoral Council (IVEC). Prior to the adoption of the amendments to the Electoral Cod, introducing specific Internet voting legislation, the opinions of the Venice Commission and OSCE/ODIHR shall be consulted.

\section{Conclusions}

We have carefully examined an electronic voting system as well as the pilot experiences of many countries. All this suggests that both the extremely optimistic and pessimistic positions about the effects of voting systems are overstated. We have also discussed the security requirements of electronic voting and highlighted the contradiction in some of these requirements. We presented information about limitations and suggested further works that should be done to address them. However, practical testing and pilot projects are the only ways of knowing what will work and what will not. Trials of particular methods will give the best insight into understanding what requirements must be met for modern voting to work well as well as the actual pros and cons of electoral systems. Modern electronic voting will not act as a panacea for the social causes responsible for electoral disengagement, nor will it remedy negative attitudes toward political entities. It will, however, increase voting opportunities for electors and make casting a vote more accessible. On the other hand, electronic voting will not erode democracy or result in vote buying and election fraud any more than the existing system does.

Electronic voting has been a topic of active debate, with a significant number of people believing that electronic voting cannot be trusted enough to be used for significant elections due to uncertainty in the authenticity and integrity of the machines, and the votes that have been cast using them. On the other hand, people acknowledge that paper solutions are significantly outdated and can be subject to serious manipulation from a coercer (Tarasov, Tewari, 2017).

Voting can be time consuming, inconvenient as well as expensive, especially when the voters and administrators are geographically distributed. With the rapid expansion of the Internet, electronic voting appears to be a less expensive alternative to the conventional paper voting. Electronic voting overcomes the problem of geographic distribution of voters as well as vote administrators. It also reduces the chances of errors in the voting process. Howev$\mathrm{er}$, in order for electronic voting to replace conventional mechanisms, it must provide the whole range of features that conventional voting systems have. Furthermore, due to the inherent lack of security on the Internet, electronic voting systems need to be carefully designed; otherwise these systems become more susceptible to fraud than conventional systems (Taghavi et al., 2017).

The world is in the era of globalization. Information technology has greatly affected all aspects of life, and to a large extent, this includes politics. We hereby stress the fact that, the importance and necessity of electronic online voting system cannot be overemphasized. There is no doubt that the new voting protocol has become not only simpler with higher security level, it also offers a better integration of the general public irrespective of their location. All this brings us one step closer to a feasible electronic voting system for elections in the range of operational political elections. Necessary and adequate research materials should be made available by the government in the institutions of higher learning so as to ease and assist wider and broader research in the field of Computer Science and Information Technology. The process of voter registration/revalidation should be made online. This is with a view of eliminating registration fraud and other electoral malpractices. It is also worth mentioning that, mobility difficulties will be eliminated. 


\section{References}

Barber B.R., 2003, Strong Democracy Participatory Politics for a New Age, University of California Press, Berkeley-Los Angeles-London.

Bellis M., 2000, The History of Voting Machines, Inventors. about.com (accessed 28 September).

Bonetti P., Ravaioli S., Piergallini S., 2000, The Italian academic community's electronic voting system, Computer Networks, 34(6), 851-860. doi: 10.1016/S13891286(00)00156-0.

Branscomb L.M., 2007, Elections and the Future of E-voting: Editor's Note, The Bridge, 37(2), 3-4.

Breuer F., Trechsel A.H., 2006, Report: E-Voting in the 2005 local elections in Estonia, eDemocracy Projects Council of Europe, https://www.coe.int/t/dgap/goodgovernance/Activities/E-voting/CoE_Studies/FinalReportCOE_ EvotingEstonia2005_en.asp (accessed 28 September 2019).

Caltech/MIT, 2001, Voting Technology Project Voting: What Is and What Could Be, http:vote.caltech.edu, (accessed 28 September).

Cambridge Dictionary, Cambridge University Press, https:// dictionary.cambridge.org/ (accessed 10 September 2019).

Cheng V., 2019, Voting Integrity and American Democracy, https://www.academia.edu/39720699/Voting_Integrity_and_American_Democracy_2019_1_(accessed 28 September 2019).

Chowdhury M.J., 2010, Comparison of e-voting schemes: Estonian and Norwegian solutions, http://courses.cs.ut. ee/2010/security-seminar-fall/uploads/Main/chowdhury-final.pdf (accessed 27 September 2019).

Council of Europe adopts new Recommendation on Standards for E-Voting, Council of Europe, 2017, https://www.coe. int/en/web/cm/news/-/asset_publisher/hwwluK1RCEJo/ content/council-of-europe-adopts-new-recommendation-on-standards-for-e-voting/16695?inheritRedirect=f alse (accessed 3 September 2019).

Electronic Voting in the USA, http://www.bravenewballot.org/ electronic-voting-in-usa/ (accessed 27 September 2019).

Hague B.N., Loader B. (eds.), 1999, Digital Democracy: Discourse and Decision-making in the Information Age, Routledge, New York.

Heller D.A., 2004, Certification of Voter Verified Paper Audit Trail Printer Completed, www.sos.state.nv.us (accessed 28 September).

Internet live stats, Moldova Internet Users, https://www.internetlivestats.com/internet-users/moldova/ (accessed 22 August 2019).

Khairul Anwar N., 2009, Advantages and Disadvantages of eVoting: The Estonian Experience, Nanyang Technological University, https://www.academia.edu/35246981/Advantages_and_Disadvantages_of_e-Voting_The_Estonian_ Experience (accessed 27 September 2019)

Maaten E., 2004, Towards remote e-voting: Estonian case, [in:] Electronic Voting in Europe, 83-90, https://www.semanticscholar.org/paper/Towards-Remote-E-Voting\%3A-Esto-
nian-case-Maaten/ff4d0a77e7561 e62fd0258280c0baa02d8256a03 (accessed 25 August 2019).

Market Evolution: mobile Internet Access. Chart 5. Evolution of the number of users (thousand) and penetration rates for mobile broadband, 2016, National Regulatory Agency for Electronic Communications and Information Technology of the Republic of Moldova, http://en.anrceti.md//nternet_mobil_BL\#fig5 (accessed 21 August 2019).

Moldcell (one of the 3 mobile operators) reported over 21.000 users of M-signatures, 2012, http://www.egov.md/en/projects/mobile-signature (accessed 22 August 2019).

Musiał-Karg M., 2014, Electronic Voting Selected issues concerning implementation of a new tool of civic democratic participation, [in:] M. Mokrys, S. Badura, A. Lieskovsky (eds.), The 3rd Electronic International Interdisciplinary Conference, Proceedings in Electronic International Interdisciplinary Conference, EDIS - Publishing Institution of the University of Zilina, Zilina, 311-315.

Peste 900 de mii de moldoveni au conturi pe Facebook. Câți dintre ei mai folosesc Odnoklassniki (Eng. Over 900 thousands Moldovans have Facebook accounts. How many of them use odnoklassniki), 2018, Publika, https://www. publika.md/peste-900-de-mii-de-moldoveni-au-conturipe-facebook-cati-dintre-ei-mai-folosesc-odnoklassniki_2995222.html (accessed 9 September 2019).

Statistics about Internet Voting in Estonia, Estonian National Electoral Committee, https://www.valimised.ee/en/archive/statistics-about-internet-voting-estonia (accessed 25 September 2019).

Taghavi T., Bafghi A.G., Kahani M., 2007, An Electronic Voting Scheme through Blind Signature, [in:] 12th International CSI Computer Conference (CSICC'07), https://pdfs. semanticscholar.org/bc81/b813724d94858b85ccd13e5135a91bd45ebb.pdf (accessed 29 October 2019).

Tarasov P., Tewari H., 2017, The Future of E-voting, IADIS International Journal on Computer Science and Information Systems, 12(2), 148-165.

The Constitutionality of Electronic Voting in Germany, 2009, NDI - National Democratic Institute, https://www.ndi. org/e-voting-guide/examples/constitutionality-of-electronic-voting-germany (accessed 22 August 2019).

Vino cu propuneri la Planul de acțiuni pentru o Guvernare Deschisă (Eng. Come up with proposals for the open Governance Actions Plan), 2016, Agenția de Guvernare Electronică, http://www.egov.md/ro/communication/ news/vino-cu-propuneri-la-planul-de-actiuni-pentru-oguvernare-deschisa (accessed 12 September 2019).

Wolf P., Nackerdien R., Tuccinardi D., 2011, Introducing Electronic Voting: Essential Considerations, International IDEA Publication Office, Stockholm. 